\title{
Acumulação e rentismo: resgatando a teoria da renda de Marx para pensar o capitalismo contemporâneo*
}

\author{
Rentism and capital accumulation: rescuing Marx's \\ theory of rent to think about contemporaneous capitalism
}

LEDA MARIA PAULANI**

\begin{abstract}
RESUMO: Se investigarmos a literatura crítica de extração marxista dos últimos anos, perceberemos a recorrência de alguns temas que são indicativos da forma contemporânea de operar do sistema capitalista (mercadoria conhecimento, valor agregado pela marca, financeirização). Apesar de aparentemente desconexos, os fenômenos aí envolvidos podem ser conectados teoricamente com o auxílio da teoria da renda de Marx, que aparece desenvolvida na seção VI do livro III de O Capital, e também nas Teorias da Mais-Valia. O objetivo do presente artigo é resgatar as observações existentes nesses trabalhos de Marx para pensar a interconexão entre os fenômenos contemporâneos acima referidos e a natureza do processo atual de acumulação de capital. Procurar-se-á mostrar que o rentismo é hoje um dos traços mais marcantes desse processo.

PALAVRAS-CHAVE: rentismo; teoria da renda de Marx; financeirização; mercadoria conhecimento.
\end{abstract}

ABSTRACT: The investigation of Marxist literature in recent years reveals the recurrence of certain themes that are indicative of the contemporary way of working of the capitalist

\footnotetext{
* Este trabalho é parte de uma pesquisa maior que procura discutir as relações entre financeirização e rentismo e que conta com o suporte de uma bolsa de produtividade do CNPq. Por seu caráter eminentemente teórico serve igualmente de base para uma pesquisa derivada dessa que procura estabelecer as relações entre rentismo e classes sociais e que fez parte de projeto temático financiado pela FAPESP, da qual sua autora participou como uma das pesquisadoras líderes. Agradeço ao Prof. Paulo Arantes ter me incentivado a escrevê-lo, aos participantes do grupo dos seminários das quartas, que ele mantém há mais de uma década na FFLCH-USP, por terem debatido comigo as idéias iniciais, e aos participantes do CAFIN, Grupo de Pesquisa sobre Instituições do Capitalismo Financeiro, registrado no CNPq, que coordeno na FEA-USP, em especial a Rodrigo A. Teixeira, Christy G. Pato, Tomas N. Rotta, Marisa S. Amaral e Leonardo A. P, Müller pelas leituras e sugestões. Os equívocos são meus.

** Professora titular do Departamento de Economia da Faculdade de Economia e Administração da Universidade de São Paulo - FEA/USP e da Pós-graduação em Economia do Instituto de Pesquisas Econômicas - IPE/USP. E-mail: paulani@uol.com.br. Submetido: 23/Maio/2012; Aprovado: 26/Agosto/2015.
} 
system (commodity-knowledge, value added by brand, financialization). Although seemingly unrelated, these phenomena can be theoretically connected with the aid of Marx's theory of rent, as it appears in Section VI of Book III of Capital, and in Theories of Surplus Value. The purpose of this article is to rescue Marx's observations in these works to think about the interconnectedness of the contemporary phenomena mentioned above and the nature of the current process of capital accumulation. This theoretical exercise seems to show that the rent seeking is, nowadays, one of the most striking features of this process.

KEYWORDS: rent-seeking; Marx' theory of income; financialization; merchandise knowledge.

JEL Classification: B14; E40; P16.

\section{UMA TAXONOMIA DAS POSSÍVEIS CONFIGURAÇÕES DOS RENDIMENTOS A PARTIR DA TEORIA DA RENDA DE MARX}

\section{Caso 1: lucro normal (caso básico)}

Marx, como se sabe, estabelece uma primeira grande divisão do valor gerado pela produção: a parcela constituída pelo trabalho necessário e a parcela constituída pelo trabalho excedente. O salário é, portanto, a primeira importante categoria de rendimento que é preciso considerar, consistindo na porção do valor produzido que é necessária para reproduzir o valor da força de trabalho (ou seja, do capital variável), revertendo assim a seu dono. Tudo aquilo que ultrapassa esse valor é trabalho excedente (não pago), que, tomando inicialmente a forma de mais-valia, vai aparecer efetivamente como lucro, já que os valores são transformados em preços de produção. O primeiro lucro que aparece é aquele resultante da taxa média que cabe a cada porção de capital, uma vez filtrados todos eles pelo processo de concorrência intercapitalista. Setorialmente, a efetividade dessa taxa normal é o resultado da imposição rigorosa do tempo de trabalho socialmente necessário (o tempo-padrão, correspondente à produtividade do trabalho comumente encontrada nas unidades produtivas de cada setor), espada de Dâmocles que pende sobre a cabeça dos donos do capital, e da qual cada um deles tenta fugir como o diabo da cruz. O sucesso na efetivação dessa taxa demonstra que as rotas de fuga não funcionaram e que o tempo de trabalho necessário, socialmente determinado, conseguiu se impor. Portanto, neste primeiro caso - o caso básico que constitui a regra teórica para os demais - o valor total produzido é dividido em duas categorias de rendimento (salário e lucro), as quais derivam do processo mesmo da produção capitalista, sendo internos a ele.

\section{Caso 2: sobrelucro}

Neste segundo caso, o valor produzido também será dividido em salário e lucro, mas, diferentemente do caso básico, o lucro agora contém o lucro normal (aquele derivado do tempo de trabalho socialmente necessário), mais um lucro extra ou so- 
brelucro. Como esclarece Marx no capítulo X do livro I de O Capital, a redução do tempo de trabalho necessário para produzir os bens é tendência imanente da produção capitalista, tendência que se explica pela necessidade imperiosa que cada capitalista tem de reduzir o tempo de trabalho individual de sua mercadoria perante ao tempo de trabalho socialmente determinado, auferindo assim um lucro extra.

Para compreender melhor, tomemos como exemplo a produção de um bem B qualquer e suponhamos que seu preço de produção é $\mathrm{x}$, que seria então o preço regulador do mercado (para não embaralhar indevidamente a análise, vamos supor daqui para a frente, salvo menção em contrário, que o preço de mercado é sempre igual ao preço de produção do bem). Isso significa que todos os produtores receberão x para cada unidade vendida do bem B. Suponhamos agora que o produtor $\mathrm{Z}$ tenha um preço de produção individual y que é menor do que $\mathrm{x}$, porque, por exemplo, fez uma transformação gerencial que elevou a produtividade do trabalho em sua empresa. Como socialmente o preço de produção de B continua sendo $\mathrm{x}, \mathrm{o}$ produtor $\mathrm{Z}$ se apropria da diferença entre $\mathrm{x}$ e y. Formalmente temos:

$$
\begin{aligned}
& \mathrm{ppB}=\mathrm{pmB}=\mathrm{x} \quad(\mathrm{I}) \\
& \mathrm{ppBz}=\mathrm{y}<\mathrm{x} \quad \text { (II) } \\
& \mathrm{Lz}=1+(\mathrm{x}-\mathrm{y}) \quad \text { (III), } \quad \text { onde: } \\
& \mathrm{ppB}=\text { preço de produção de uma unidade de } \mathrm{B} \text { (ou preço regulador de } \mathrm{B} \text { ) } \\
& \mathrm{pmB}=\text { preço de mercado de uma unidade de } \mathrm{B} \\
& \mathrm{ppBz}=\text { preço de produção de uma unidade de } \mathrm{B} \text { para o produtor } \mathrm{Z} \\
& \mathrm{Lz}=\text { lucro total do produtor } \mathrm{Z} \text { por unidade vendida de } \mathrm{B} \\
& 1 \text { = lucro normal por unidade vendida de B (lucro relativo ao preço regulador de B, que é x) }
\end{aligned}
$$

A diferença entre $\mathrm{x}$ e $\mathrm{y}$, da qual se apropria nosso produtor Z, é um sobrelucro, que ele conseguiu obter graças às inovações que introduziu em seu processo de produção e das quais se beneficiará enquanto o preço regulador de B (seu preço geral de produção) continuar a ser $\mathrm{x}$. Todo o valor produzido se divide assim em salário e lucro, sendo, apenas teoricamente, este último dividido em lucro normal e sobrelucro. Tal como no caso anterior, não temos aqui nenhuma parcela do valor produzido que tenha se transformado num pagamento cujo fundamento seja a mera propriedade.

\section{Caso 3: metamorfose do sobrelucro em renda fundiária - renda diferencial por diferenças naturais de produtividade (caso ricardiano) ${ }^{1}$}

Suponhamos agora que o bem B seja um produto agrícola, por exemplo, trigo. Neste caso, para além das diferenças que possam ser buscadas entre o preço de produção individual e o preço geral de produção, existe uma outra diferença, que

\footnotetext{
${ }^{1}$ A abordagem deste caso, bem como dos dois subsequentes está baseada inteiramente em Harvey (2006).
} 
não advém, contudo, do andamento do processo de produção em si, mas de fertilidades distintas que as diferentes faixas de terra possam apresentar. Nesse caso, a produtividade maior de uma determinada terra faz com que seja embolsado como renda fundiária o excedente do preço regulador do trigo sobre o preço de produção dessa faixa.

Ricardo foi quem consagrou a discussão relativa a este caso no famoso Ensaio sobre a influência do baixo preço do cereal nos lucros do capital, escrito em 1815. Ele argumenta que o crescimento da população e a consequente necessidade de uma quantidade crescente de alimentos faria com que fossem ocupadas terras cada vez menos férteis. Como o preço regulador do cereal seria dado pela produtividade do trabalho na pior terra, toda a diferença de produtividade existente nas faixas mais férteis seria embolsada como renda por seus proprietários. Marx vai concordar, em parte, com a análise de Ricardo, discordando, porém, de sua proposição de que a única renda fundiária possível seria a renda diferencial. Para ele, há razões suficientes para afirmar a existência também de uma renda absoluta (caso que veremos mais à frente). Contudo, há outros elementos nessa discordância de Marx com Ricardo. Antes que tratemos deles, porém, vejamos como funciona essa renda diferencial e como ela é, num sentido, análoga ao lucro extra do caso anterior, e, em outro sentido, completamente diferente dele.

Suponhamos que na região produtora de trigo de um dado país existam apenas duas faixas de terra, sendo A a mais fértil. Nesse caso, o preço regulador do trigo, que será decomposto apenas em salário e lucro, será dado pela produtividade do trabalho na faixa B. Formalmente temos:

$$
\begin{array}{ll}
\text { pptrigo } \mathrm{B}=\text { pptrigo }=\text { pmtrigo }=\mathrm{x} & (\mathrm{IV}) \\
\text { pptrigo } \mathrm{A}=\mathrm{y}<\mathrm{x} & (\mathrm{V}) \\
\mathrm{La}=1+(\mathrm{x}-\mathrm{y}) & (\mathrm{VI}), \text { onde: }
\end{array}
$$

pptrigoB $=$ preço de produção de uma unidade de trigo na faixa $\mathrm{B}$

pptrigo $=$ preço de produção de uma unidade de trigo (ou preço regulador do trigo) pmtrigo $=$ preço de mercado de uma unidade de trigo pptrigo $\mathrm{A}=$ preço de produção de uma unidade de trigo na faixa $\mathrm{A}$

$\mathrm{La}=$ lucro total do produtor que opera na terra A por unidade vendida de trigo $\mathrm{I}$ = lucro normal por unidade vendida de trigo (lucro relativo ao preço regulador do trigo, que é $\mathrm{x}$ )

Assim, produzindo-se trigo na faixa de terra $\mathrm{A}$, a produção gera como valor excedente não apenas o lucro normal (1), mas também um adicional derivado da diferença entre as produtividades das duas faixas de terra. Do ponto de vista formal, trata-se de caso idêntico ao anterior: o preço de produção individual de um produtor é inferior ao preço de produção que funciona como preço regulador do mercado (matematicamente as equações I, II e III são exatamente iguais às equações IV, $\mathrm{V}$ e VI). A única diferença é que, no primeiro caso, a diferença entre os dois preços deve-se a alterações introduzidas no processo produtivo por um dos produtores, 
enquanto no segundo ela se deve a diferentes fertilidades da terra, um elemento, portanto, que não foi introduzido pela atuação dos agentes envolvidos na produção, mas foi "produzido" pela própria natureza.

Nas condições da produção capitalista, porém, essa diferença de origem acaba por fazer toda a diferença, tornando distintos os dois casos e fazendo aparecer na história um tipo de rendimento, a renda fundiária, que, diferentemente do salário e do lucro, não está relacionado ao processo de produção enquanto tal, mas à propriedade privada da terra, um elemento, portanto, externo a ele. Dá-se o nome de renda ao rendimento que deriva da mera propriedade, ou seja, é rentista todo aquele que tem direito a uma parcela do valor socialmente produzido pelo mero fato de ser proprietário. Dono de terra é rentista, porque a renda fundiária que lhe é devida liga-se ao fato de ser proprietário de uma dada porção do globo terrestre (que pode ser explorada capitalistamente). Dono de capital monetário é rentista, porque o juro que lhe é devido liga-se ao fato de ser dono de um montante de dinheiro (que pode ser empregado como capital). Mas há uma diferença importante entre o juro e a renda fundiária. No caso da renda fundiária, está relacionada à figura da propriedade a figura do monopólio. O que produz a renda fundiária na terra mais fértil não é a apropriação de uma força natural que torna mais produtiva a força de trabalho, mas a apropriação de uma força natural que não está à disposição de todo o capital investido na mesma esfera de produção, "uma força natural monopolizável que [...] só está à disposição daqueles que dispõem de certos trechos do globo terrestre" (Marx, 1985/1894, pp. 144-145).

É exatamente essa condição de recurso natural limitado e monopolizável que transforma em renda fundiária o sobrelucro auferido em função de sua existência, pois ele cabe justamente a seu dono, ou seja, àquele que tem o monopólio dessa força natural. ${ }^{2}$ Como observa Marx, é a propriedade fundiária que dá condições ao proprietário de atrair o sobrelucro do bolso do fabricante para o seu, sendo por isso a causa de sua metamorfose em renda fundiária (idem, p. 146). Na explicação do surgimento da renda fundiária, não é a diferença natural (fertilidades distintas) que importa, mas sua condição de ser monopolizável. Ao não ter clareza disso, Ricardo julgou que a renda fundiária era resultado apenas da existência de diferenças naturais. Não pôde, por isso, perceber que esse tipo de rendimento pode existir, e existe, também sob a forma absoluta, sendo essa a prova maior de que "a apropriação da renda é a forma econômica em que a propriedade fundiária se realiza" (idem, p. 137), sendo que uma pressupõe a outra. Discutiremos a renda absoluta posteriormente. Vejamos antes outro tipo de renda diferencial discutido por Marx.

\footnotetext{
2 “A força natural não é a fonte do sobrelucro, mas apenas a base natural dele, pois é a base natural da força produtiva do trabalho excepcionalmente mais elevada" (Marx, 1985/1894, p.145).
} 


\section{Caso 4: metamorfose do sobrelucro em renda fundiária - renda diferencial por diferenças de produtividade artificialmente obtidas}

Diferentemente de Ricardo, Marx refere-se também a um tipo de renda diferencial que pode provir não dos acasos da natureza, mas da aplicação de diferentes montantes de capital em faixas de terra de igual fertilidade. ${ }^{3}$ Nas terras onde capital acima do normal é investido, o preço individual de produção fica abaixo do preço regulador do produto, permitindo a produção de um valor excedente adicional. Neste caso, porém, tudo se assemelha ao Caso 2, um caso normal de sobrelucro, produzido pela interferência de um dos agentes da produção. Marx assegura, porém, que, em determinadas condições, essa diferença (ou ao menos parte dela) pode ser apropriada como renda fundiária.

O problema aqui é que, diferentemente do que ocorre no caso das diferenças produzidas pela natureza, o diferencial de produtividade assim obtido não é permanente. Quais são as condições que transformam essa situação? Uma primeira resposta de Marx é que, a depender do tipo de capital aplicado, o aumento obtido na produtividade adquire caráter permanente, pois o capital adicionado fica incorporado (fixado, preso) no terreno, como, por exemplo, sistemas de irrigação ou celeiros. Essas melhorias, uma vez incorporadas ao local, apesar de terem sido produzidas pelo capital, vão funcionar como diferenciais de fertilidade, pois a produtividade do trabalho nos terrenos em que elas existem será maior do que a implícita no preço regulador do bem agrícola. Sendo assim, os valores excedentes adicionais então produzidos poderão ser apropriados como renda. O que torna essa possibilidade menos efetiva é o fato de o arrendatário (o produtor capitalista) não poder se apropriar inteiramente do retorno desse tipo de investimento, o que o desestimula. Daí, como lembra Marx, a permanente luta dos arrendatários por contratos de arrendamento longos (Marx, 1985/1894, p. 166).

Mas é o segundo caso desse tipo, mais complexo, que mais chama a atenção de Marx. O pressuposto inicial é que não há como se conhecer as diferentes fertilidades dos solos sem que se apliquem capitais neles e, por conta disso, aquilo que deve ser considerado como um montante "normal" de capital varia de solo para solo. No bom resumo de Harvey, "o conceito de capital 'normal' torna-se tão variado quanto a variada fertilidade dos solos nos quais ele é aplicado. $\mathrm{O}$ caso "normal' é, portanto, o da desigual aplicação de capital em solos de fertilidade desigual" (2006, p. 356). Assim, se antes, na consideração do primeiro tipo de renda diferencial, Marx, pela inclusão das considerações relacionadas à localização, já havia podido discordar da clara e ordenada progressão ricardiana em direção a terras menos férteis, aqui ele vai poder demonstrar, contrariando Ricardo mais uma vez,

\footnotetext{
${ }^{3}$ Cabe observar que também Ricardo fez exercícios demonstrando os resultados da aplicação de parcelas adicionais de capital numa mesma faixa de terra. Mas ele o fez no intuito de demonstrar a chamada lei dos rendimentos decrescentes, não para considerar a possibilidade de uma apropriação de renda fundiária por conta dos montantes de capital investido.
} 
que vários resultados podem ocorrer em função da aplicação de porções adicionais de capital: o pior solo pode ser abandonado, ou pode continuar, como antes, funcionando como a base do preço regulador do bem agrícola, ou, ainda, pode ser substituído, nesse papel, por um solo de qualidade ainda inferior (se capital adicional for investido na pior terra em cultivo).

Um resultado interessante que se pode tirar daí é que a continuidade da aplicação de porções adicionais de capital nas melhores terras (situação bastante plausível), pode levar, mesmo na hipótese de rendimentos decrescentes dessas aplicações, a uma redução do preço regulador do bem, em função de seu deslocamento para melhores solos. Nesse caso, o aumento da renda diferencial do segundo tipo é contrabalançado pela redução da renda diferencial do primeiro tipo, mostrando, como queria Marx, que os dois tipos de renda diferencial servem de limites um ao outro, tornando-se opaca a verdadeira base da apropriação de renda (Harvey, 2006, p. 357).

Estudados os dois casos de renda diferencial, podemos analisar o caso da renda absoluta, que dará em seguida o gancho para que discutamos o último caso, o da renda de monopólio.

\section{Caso 5: metamorfose da mais-valia agrícola em renda fundiária: renda absoluta}

$\mathrm{Na}$ discussão sobre a existência ou não de uma renda absoluta, Marx começa observando que, na hipótese de ser falso o pressuposto de que o pior solo em cultivo não gera renda, o preço do bem agrícola necessariamente se situará acima do preço de produção (que envolve apenas salário e lucro), o que, no entanto, não alteraria a lei da renda diferencial. Deduz daí que a questão a ser respondida diz respeito aos fundamentos desse pressuposto. Em outros termos, a pergunta que Marx faz é a seguinte: considerando-se que o preço de mercado do bem agrícola tenha alcançado nível suficiente para pagar o salário do trabalho e produzir o lucro médio na pior faixa de terra, isso será suficiente para que capital seja investido nessa faixa? "Ou o preço de mercado precisa subir até o ponto em que mesmo o pior solo proporcione renda? Será que, portanto, o monopólio do proprietário da terra estabelece um limite ao investimento de capital que, do ponto de vista puramente capitalista, não existiria na ausência desse monopólio?” (Marx, 1985/1894, p. 223). E continua: "Posto o caso em que a demanda exige a incorporação de novas terras, menos férteis [...] então o proprietário as arrendará de graça, pois o preço de mercado do produto agrícola subiu o suficiente para que o investimento de capital nesse solo pague o preço de produção, proporcionando assim o lucro corrente?". E responde: "De jeito algum. O investimento de capital precisa proporcionar-lhe renda. Ele só arrenda suas terras quando um arrendamento pode ser pago" (idem, p. 225).

A partir daí Marx afirma que a propriedade fundiária, ou seja, o monopólio do proprietário sobre determinadas áreas do globo, funciona como uma "barreira", um "obstáculo", uma "força estranha", com a qual se depara o capital em seus investimentos na terra (idem, p. 228). Esse obstáculo, que confere ao preço do bem agrícola as características de um preço de monopólio, põe por terra o pressuposto 
ricardiano de que a terra de pior qualidade não paga renda. Mostra-se com isso a necessidade de incluir no conjunto de rendimentos proporcionados pela terra também uma renda que se deve tão somente ao instituto da propriedade privada, ou seja, uma renda absoluta. Formalmente temos:

$$
\begin{array}{ll}
\text { ppba }=\mathbf{x} & \text { (VII) } \\
\text { pmba }=\mathbf{y}>\mathbf{x} & \text { (VIII) } \\
\text { Lba }=1+(y-x) & (\text { IX) } \\
\mathbf{y}-\mathbf{x}=\mathbf{r} & \text { (X), onde: }
\end{array}
$$

ppba $=$ preço de produção de uma unidade do bem agrícola

pmba $=$ preço de mercado de uma unidade do bem agrícola

$\mathrm{Lba}=$ lucro total do produtor por unidade vendida do bem agrícola

1 = lucro normal por unidade vendida do bem agrícola

(lucro médio relativo ao preço de produção do bem agrícola, que é x)

$\mathrm{r}=$ renda fundiária (absoluta)

Nos termos de Marx, isso significa que a propriedade privada da terra ergue barreiras ao processo de equiparação na distribuição intersetorial da mais-valia gerada pelo capital global. Como se sabe, a concorrência intercapitalista é o motor que conduz esse processo e que opera a transformação dos valores em preços de produção. Sobre isso, Marx lembra que é tendência dos capitais superar todos os obstáculos a essa equiparação, tolerando apenas os sobrelucros que se originem da diferença entre o preço de produção geral e os preços individuais de produção, sobrelucros, portanto, que só podem ocorrer dentro de cada esfera de produção (idem, pp. 227-228). A propriedade fundiária introduz um elemento novo nessa regra, pois que viabiliza a permanência de "sobrelucros" que se originam da diferença entre valores e preços de produção e que, portanto, podem ocorrer entre diferentes esferas.

Assim, tudo se passa como se a propriedade fundiária, por sua mera existência, conseguisse capturar e reter sob a forma de renda fundiária ao menos uma parte do excedente de valor dos bens agrícolas sobre seus preços de produção, excedente que sempre existe, tendo em vista que a composição orgânica do capital na agricultura é tradicionalmente inferior à dos demais setores. Em outras palavras, a barreira erguida pela propriedade privada da terra impede que seja oferecida à equiparação orquestrada pela concorrência a integridade da parcela do valor produzido na atividade agrícola que excede os preços de produção. Assim, podemos definir a renda absoluta como uma metamorfose da mais-valia agrícola, transformação de uma parte dessa mais-valia em renda fundiária.

A existência de circunstâncias que impedem determinados preços de descerem ao nível que seria determinado pelo preço de produção é característica dos chamados preços de monopólio, daí por que o preço do bem agrícola, no caso da existência da renda absoluta, poder ser assim considerado. Contudo, há uma profunda 
diferença de natureza entre esse preço e um verdadeiro preço de monopólio, o qual gera um tipo de renda completamente diferente e que veremos a seguir.

\section{Caso 6: renda de monopólio}

Para discutir este último caso, suponhamos agora a produção de vinho. ${ }^{4} \mathrm{Su}$ ponhamos também que exista, na mesma região A de um país produtor dessa mercadoria, um produtor $\mathrm{W}$ que tem a sorte de ser dono de uma terra de excepcional qualidade para a produção da uva dessa região. Essa excepcional qualidade, porém, não é devida à maior produtividade da terra (no sentido quantitativo, de produzir por hectare maior quantidade de uvas que as demais), mas à qualidade diferenciada, excepcional, da uva ali produzida, que possibilita o fabrico de um vinho também de excepcional qualidade. Neste caso, nosso produtor $\mathrm{W}$ vai se beneficiar dessa situação, que foge da regra da produção dos vinhos da região $\mathrm{A}$. O que vai ocorrer é que a qualidade excepcional do vinho produzido por $\mathrm{W}$ vai possibilitar que ele seja vendido por um preço cuja determinação não será dada pelo tempo de trabalho, nem socialmente nem individualmente determinado. Funcionando como um preço de monopólio, ele será determinado pela disposição a pagar daqueles que desejarem obter os escassos exemplares produzidos. Como observa Marx, as rendas diferencial e absoluta são as únicas formas normais de renda. "Fora delas, a renda só pode basear-se num autêntico preço de monopólio, que não é determinado nem pelo preço de produção, nem pelo valor das mercadorias, mas pela necessidade e pela capacidade de pagar dos compradores." (Marx, 1894/1985, pp. 229-230). Formalmente temos:

$$
\begin{array}{ll}
\text { ppA }=\operatorname{pmA}=\mathrm{x} & (\mathrm{XI}) \\
\operatorname{pmAw}=\mathrm{y}>\mathrm{x} & (\mathrm{XII}) \\
\mathrm{Lw}=1+(\mathrm{y}-\mathrm{x}) & (\mathrm{XIII}), \quad \text { onde: }
\end{array}
$$

ppA = preço de produção de uma unidade do vinho da região A (vinho A)

$\mathrm{pmA}=$ preço de mercado de uma unidade do vinho $\mathrm{A}$

$\mathrm{pmAw}=$ preço de mercado de uma unidade do vinho $\mathrm{A}$ produzido pelo produtor $\mathrm{W}$

$\mathrm{LW}=$ lucro total do produtor $\mathrm{W}$ por unidade vendida de seu vinho

$\mathrm{I}=$ lucro normal por unidade vendida do vinho A

(lucro relativo ao preço regulador do vinho A, que é x)

O conjunto de equações acima mostra que, tanto no caso da renda absoluta, quanto no caso da renda de monopólio, formalmente o que está acontecendo é a mesma coisa, ou seja, o produtor se beneficia do fato de o preço de mercado do bem que produz se situar, digamos assim, estruturalmente acima do preço de pro-

\footnotetext{
${ }^{4}$ Vinho de excepcional qualidade é o exemplo utilizado por Marx para explicar a situação em tela (idem Marx, 1985/1894, p. 239, e Harvey, 2006, pp. 349-350)
} 
dução. Mas, cabe então perguntar: categorialmente, o que é a diferença y - x que faz aumentar o lucro do produtor W? É um ganho que deriva do monopólio, pois só o produtor W tem esta terra excepcional tornando-se, portanto, um monopolista na produção do vinho da região A com essa qualidade. O preço do vinho A do produtor W é um típico preço de monopólio, ou seja, seu único limite é estabelecido pela disposição a pagar dos potenciais compradores dessa mercadoria. ${ }^{5}$

Assim, apesar de formalmente termos a mesma situação (as equações VII, VIII e IX são idênticas, do ponto de vista matemático, às equações XI, XII e XIII) a razão de sua existência é distinta em cada um dos casos. Marx vai observar, como lembra Harvey, que, no primeiro caso, é a imposição da renda que gera o "preço de monopólio", enquanto no segundo se dá o inverso: o preço de monopólio é que gera a renda.

\section{RENDIMENTOS DERIVADOS DA PRODUÇÃO E RENDIMENTOS DERIVADOS DA PROPRIEDADE}

Consideradas as categorias de renda aqui relembradas (renda diferencial de dois tipos, renda absoluta e renda de monopólio), mais o juro, o lucro, o sobrelucro e o salário, temos então o universo possível de diferentes categorias de rendimento que podem ser teoricamente deduzidas dos princípios básicos da teoria do valor de Marx. De nosso ponto de vista, a divisão que importa fazer entre eles é aquela que coloca, de um lado, as categorias que derivam do processo de produção em si e que têm sua magnitude determinada pela forma de sua condução, e, de outro, as categorias que derivam da mera propriedade e que têm sua magnitude determinada por variáveis que são, na maior parte dos casos, externas a esse processo. No primeiro caso temos o salário, o lucro e o sobrelucro; no segundo, o juro e todas as categorias de renda.

O salário, reprodução do valor da força de trabalho, só se efetiva se o trabalho vivo funcionar e isso só acontece no processo de produção. O lucro é trabalho não pago, ou seja, tempo de trabalho despendido na produção que acarreta remuneração para o dono dos meios de produção, portanto, um tipo de rendimento igualmente derivado do processo produtivo em si, o mesmo valendo para o sobrelucro.

A renda diferencial é também sobrelucro, só que sobrelucro apurado no setor agrícola, onde a terra faz parte do conjunto dos meios de produção. A existência da propriedade privada da terra faz com que esse valor, produzido no processo produtivo, gerado, portanto, pelo trabalho, e gerado num nível que supera o do pagamento do salário somado ao lucro médio, seja apropriado não como sobrelucro, mas como renda fundiária. Surge na trama, portanto, uma nova classe de personagens e um novo tipo de rendimento. A renda fundiária, que é devida ao

\footnotetext{
${ }^{5} \mathrm{O}$ lucro normal que aparece na equação XIII é apenas uma notação teórica, uma vez que todos os vinhos da região podem ser comparáveis entre si.
} 
dono da terra e que tem no sobrelucro sua base material, é rendimento que deriva da mera propriedade. Os proprietários fundiários, graças ao monopólio que têm de "determinadas partes do globo terrestre e seus anexos", para usar os termos de Marx, capturam parte do valor gerado em sua porção de terra e se apropriam dele sob a forma de renda. São, portanto, rentistas. ${ }^{6}$

No caso da renda absoluta, essas últimas observações se colocam com a mesma pertinência. Os donos de terra capturam uma parte do valor gerado em seu território e se apropriam dele sob a forma de renda. São, portanto, rentistas, e seu "direito" a essa renda deve-se ao fato de serem proprietários de uma parte do globo. A diferença é que, ao invés de o proprietário simplesmente se apossar de uma parcela do valor gerado que, de outra forma, seria apropriado pelo arrendatário capitalista como sobrelucro, ele impede que uma parcela do valor excedente produzido em sua terra seja oferecida ao processo de equiparação na distribuição da mais-valia gerada pelo capital global. Em função disso, reduz-se a massa de valor excedente que vai servir de base para a construção da taxa média de lucro, reduzindo-se, portanto, essa taxa em relação ao que ela poderia ser na ausência dessa captura. Nesse sentido, apesar de o dono de terra estar retendo para si parte do valor gerado em seu território, ele não está surrupiando esta porção de valor apenas do arrendatário capitalista que explora suas terras, mas de toda a classe burguesa. É claro que há limites à existência da renda absoluta, o mais visível deles sendo a manutenção, no setor agrícola, de uma composição orgânica do capital inferior à dos demais setores, o que fica comprometido pelo progresso tecnológico. Mas, como veremos à frente, esse tipo de renda está reaparecendo de forma transformada.

No caso da renda de monopólio, apesar de a mesma poder ser igualmente atribuída à mera propriedade, ela requer condições que estão diretamente ligadas ao processo de produção. É verdade que o produtor que se apropria dela não tem tal prerrogativa em função de ter introduzido alterações que tenham elevado a produtividade do trabalho. Mas ele assenta esse direito no fato de ter o monopólio alguma condição de produção que possibilita o fabrico de bens excepcionais. Aqui, dada a condição de monopolista do produtor, o tempo de trabalho socialmente necessário coincide com o tempo de trabalho individual, o que significa que ele não existe, ou seja, ele não funciona, para o produtor, como uma regra impositiva, que obriga a adequação do processo produtivo àquilo que é posto socialmente como norma. Assim, a renda da qual o produtor em tal condição se apropria é equivalente ao excedente do preço de mercado alcançado pelo bem relativamente àquele que ele deveria ter se tal condição não existisse.

Marx observa nos capítulos iniciais de O Capital, que a quantidade de valor produzida num determinado período de tempo, por exemplo, uma hora, é sempre a mesma, ou seja, o que muda entre processos mais e menos produtivos é a quan-

\footnotetext{
${ }^{6}$ A situação aqui discutida vale para todos os setores, não apenas para o agrícola, pois a questão da localização do processo produtivo é de vital importância para a determinação da rentabilidade do negócio.
} 
tidade de valores de uso que se produz, por período, em cada um deles. No caso da renda de monopólio, essa regra não vale, pois tudo se passa como se os trabalhadores desses processos excepcionais produzissem, pelo efeito de alguma condição mágica, mais valor (e às vezes muito mais valor) por unidade de tempo do que os demais trabalhadores. Como quem tem a posse dessa condição mágica é o produtor, é a ele que cabem os ganhos daí derivados e ele se apropria desses ganhos sob a forma de uma renda de monopólio. Não se trata aqui, portanto, como na renda absoluta, de a posição monopolista permitir a captura de uma porção de valor que de outra forma não lhe seria acessível, mas de a posição monopolista permitir a retenção integral para si do excesso de valor que tal condição excepcional de produção propicia, excesso esse que não existiria, como valor produzido, na inexistência dessa condição especial. Tal como ocorre com a fertilidade do solo, também aqui a mencionada condição mágica não é a fonte da renda de monopólio, mas apenas a base dela, pois é a base do valor magicamente mais elevado que a força de trabalho cria. ${ }^{7}$

Para completar nosso quadro, falta avaliar o juro. Como já adiantado, o juro é a renda que o capital monetário propicia a seu detentor pelo mero efeito da propriedade. É bem conhecida a passagem do capítulo 23 do Livro III de O Capital em que Marx se pergunta por que razão a mera divisão do valor excedente entre dois personagens resulta em duas coisas de natureza distinta: "A pergunta que surge então é a seguinte: como essa divisão puramente quantitativa do lucro em lucro líquido e juro se transforma em qualitativa? Em outras palavras, como explicar que também o capitalista que emprega apenas capital próprio e nenhum emprestado classifique parte de seu lucro bruto na categoria particular de juro e, como tal, a calcule separadamente?" (Marx, 1984/1894, p. 278).

Em outras palavras, Marx indaga por que razão nada muda na história se esses dois personagens (que nas Teorias da Mais-Valia ele chama de capitalista jurídico e capitalista econômico) forem interpretados pela mesma pessoa. Que é realmente assim que tudo se passa é comprovado pelo fato de atualmente, nas legislações tributárias de boa parte dos países, ser permitida a exclusão do valor relativo aos "juros sobre o capital próprio" do montante de lucros auferido pelas empresas, para efeitos de incidência dos impostos sobre a renda. Marx, premonitoriamente, adiantou aqui o "fundamento" dessa regra. Em O Capital, a resposta que ele dá à pergunta em tela é que o capital, "em relação às categorias de lucro que proporciona, se decompõe em propriedade do capital, capital fora do processo de produção, que proporciona juro em si e capital dentro do processo de produção, que como processante proporciona ganho empresarial" (idem, p. 281, itálicos nossos). Portanto, assim como a propriedade da terra proporciona renda fundiária e

\footnotetext{
${ }^{7}$ Pode-se falar aqui, como Prado (2005), numa "desmedida do valor", porque uma condição "mágica" interfere no processo e impede o tempo de trabalho de funcionar como parâmetro do valor (preço de produção) das mercadorias.
} 
a propriedade de condições excepcionais proporciona renda de monopólio, a propriedade do capital enquanto tal proporciona uma renda chamada juro.

Antes de adentrarmos às considerações finais, vale mencionar um outro tipo de divisão do lucro, sobre o qual até agora não tratamos. Trata-se do "dividendo", mais uma parcela do valor excedente auferido pelas empresas que se relaciona ao capital como propriedade e não como meio de produção. Dividendo, como se sabe, é o nome que recebe a remuneração que é destinada aos proprietários de ações. Uma vez que se decida por sua distribuição, qualquer proprietário de ação tem direito a ele, pelo simples fato de ser proprietário, mesmo que seja um proprietário eventual que acabou de comprar esses títulos na Bolsa, mesmo que não tenha a menor ideia sobre qual é o tipo de negócio que a empresa desenvolve, mesmo que ignore sua forma de trabalho, mesmo que desconheça seu endereço. O caráter externo do direito a esse recurso é, portanto, evidente. A remuneração dos acionistas faz com que, além do juro, uma outra parcela do lucro, aquela que se resolve em pagamento de dividendos, vincule-se ao capital como propriedade.

Realizado, assim, a partir de Marx, o inventário das diferentes categorias de rendimento ensejadas pela produção capitalista, vejamos como esse quadro nos ajuda a entender a forma contemporânea de operar do capitalismo, particularmente alguns dos fenômenos que lhe são mais característicos.

\section{CAPITALISMO CONTEMPORÂNEO E RENTISMO}

No prefácio de Limits to Capital que escreve para a reedição de 2006 (a obra original é de 1982), Harvey afirma que, muito longe da eutanásia do rentier que Keynes vislumbrou, o poder das classes burguesas está crescentemente articulado em torno a pagamentos de rendas, sejam elas provenientes da exploração de recursos naturais, da criação de monopólios, da existência de diferenciais de produtividade, ou das mais diferentes formas de rent seeking (2006/1982, p. xvi). A definição de finança (no singular) que adotam Duménil e Lévy joga água no mesmo moinho. Para eles, ela pode ser definida como "o conjunto formado pelas frações superiores da classe capitalista mais as instituições financeiras, entendidas como encarnações e agentes do poder dessas frações", sendo que a característica principal que tem o capital para esta burguesia é sua materialização na posse de títulos, ações e direitos creditícios, ou seja, ativos financeiros com direito a renda de variados tipos (2010, pp. 187-189). Outros autores como Prado (2005), Chesnais (2010) e Husson (2010) vão em direção similar. Em seu conjunto, essas considerações indicam a presença, no capitalismo de hoje, de um fortíssimo traço rentista, rentismo esse que é agora constitutivo do processo de acumulação, e não um "pecado contra a acumulação", como chegou a ser interpretado pela Economia Política quando de seu nascimento. $\mathrm{O}$ resgate da teoria da renda de Marx aqui efetuado ajuda-nos a fundamentar teoricamente esse traço. Cabe, pois, mostrar de que maneira determinados fenômenos característicos desta etapa atual vinculam-se às categorias de rendimento apresentadas na primeira seção. 
Começamos com a questão da exploração dos recursos naturais, associada que está às rendas diferenciais do primeiro tipo, ou rendas diferenciais naturais. Longe de ser questão atinente apenas a determinados setores, ela é de interesse geral e está hoje imbricada na economia e na sociedade como um todo, dada a proeminência cada vez maior da problemática do meio ambiente. O rentismo envolvido na exploração econômica dos recursos contidos no subsolo é dos mais sinistros, pois aqui se trata de transformar em valor excedente recursos esgotáveis, desequilibrando a Natureza e comprometendo as possibilidades futuras de produção material.

Como se trata de recursos existentes no subsolo (minérios, petróleo), a propriedade estatal está quase sempre presente, de modo que o rentismo, neste caso, é normalmente patrocinado pelo próprio Estado. $\mathrm{O}$ exemplo brasileiro da exploração do petróleo ilustra esse tipo de rentismo. ${ }^{8}$ Respeitando o princípio de que os recursos do subsolo são de propriedade estatal, a Constituição brasileira de 1988 proibiu a celebração do chamado contrato de concessão, segundo o qual o resultado da prospecção pertence inteiramente ao concessionário, convertendo-se em sua propriedade. Nesse tipo de contrato, portanto, as rendas produzidas pelo trabalho executado no setor são inteiramente privatizadas, ao invés de ficarem sob o controle do Estado. Esse tipo de contrato é tão deletério para o país que mesmo a ditadura militar brasileira o rejeitou. ${ }^{9}$

Pois foi justamente o contrato de concessão que o governo de Fernando Henrique, fazendo tábula rasa da Constituição, assinou em 1997 (Lei 9.478/1997), não por acaso no auge das privatizações. Ora, é esse tipo de contrato o que mais combina com o processo de financeirização da economia, no qual o país entrava então aceleradamente. Ao contrário dos contratos de serviço que vinculam ao capital apenas o lucro obtido na prestação dos serviços de prospecção e exploração, o contrato de concessão atrela ao capital também as rendas produzidas no processo de exploração dos recursos. ${ }^{10}$

Num escopo mais amplo e pensando em particular nos países que não dispõem de moeda forte, Bresser-Pereira (2008) vai apontar a existência de rendas ricardianas sempre que a existência de recursos naturais abundantes (e baratos) trouxer $o$ preço da divisa que equilibra as contas externas a um nível inferior àquele necessário para viabilizar a produção interna de todos os demais setores que não dispõem desse benefício. As rendas ricardianas dependem aqui do diferencial de produtividade entre o país e o mercado internacional e das variações dos preços internacionais.

Outro tipo de exemplo é a renda diferencial derivada de diferenças de localização, a qual tem estreitas relações com as bolhas imobiliárias e as crises por elas

\footnotetext{
${ }^{8}$ Baseio-me aqui inteiramente em Bercovici (2010).

${ }^{9} \mathrm{~A}$ opção dos militares foi pelos contratos de risco, pelos quais a empresa é remunerada pelos serviços de prospecção e corre o risco de arcar com os custos dessa atividade, se petróleo não for encontrado.

${ }^{10} \mathrm{Em} 2010$ esse regime foi alterado (Lei 12.351).
} 
patrocinadas. Harvey (2006/1982), observa que Marx acrescenta, à diferença de fertilidade, a diferença de localização das faixas de terra como elemento fundante da apropriação da renda fundiária, mas não tira daí todas as consequências. $\mathrm{O}$ mesmo Harvey foi quem se encarregou de mostrar a importância da localização como geradora de renda, bem como sua complexa e profícua relação com o capital financeiro. Segundo esse autor (idem, pp. 367-372), para que desapareça a contradição entre a lei do valor e a existência da renda fundiária, a terra deve se constituir num campo aberto à circulação do capital portador de juros, ou seja, deve ser tratada como capital fictício. Isso significa que o preço da terra deve refletir a permanente busca do capital por rendas futuras aumentadas. Esse arranjo permite a coordenação do processo de utilização da terra, de modo a se garantir sempre os melhores e mais lucrativos usos e a maximizar a produção de valor excedente. A situação ideal é que toda terra seja assim encarada, de modo que todas as outras formas de propriedade da terra desapareçam.

A utilização da terra como capital portador de juros permite uma aliança ativa entre proprietários de terra e capitalistas. Os investimentos feitos na terra (construção civil, por exemplo), propiciam lucro, mas, regra geral, o aumento na renda que o investimento propicia ultrapassa em muito o lucro proporcionado por esses investimentos, pois, em geral, potencializam as diferenças naturais. A existência desse tipo de parceria, forjada principalmente pelos diferenciais de localização dos terrenos, parece a prova maior do acerto de Marx quando afirma que há uma inter-relação difícil de deslindar entre a renda diferencial de tipo 1 (aquela que tem fundamento nos diferentes tipos de terrenos naturais) e a renda diferencial de tipo 2 (aquela que tem fundamento numa diferença construída pelos investimentos). É evidente que a diferença de localização também pode, e é, em boa medida, construída, pois a melhor ou pior localização, do ponto de vista do capital, depende do próprio capital e da forma de seu desenvolvimento no espaço. Aqui, ao contrário do que acontece na agricultura, onde, a depender das circunstâncias, o incremento de um tipo de renda pode reduzir o outro, o resultado pode ser benéfico às duas rendas (leia-se a proprietários de terra e capitalistas), pois os investimentos podem não só potencializar diferenças originais de localização, como mesmo criá-las.

O importante a destacar é o caráter virtuoso da associação entre captura de renda e busca de lucro que a circulação do capital portador de juros pode propiciar, bem como a interação e reforço mútuo entre os dois tipos de renda, particularmente nas áreas urbanas. Em outras palavras, a transformação da terra num campo aberto à circulação do capital portador de juros significa não só a dominação do poder social da terra pelo poder social do dinheiro, como a subsunção da primeira ao processo de acumulação, ao atribuir aos proprietários de terra o papel ativo de dar fluidez e dinamismo ao mercado de terras.

Harvey lembra, no entanto, que, quanto mais aberto for o mercado de terras à peregrinação do capital portador de juros, tanto maior o risco de o excedente de capital monetário imprudentemente construir pirâmides de dívidas, transformando-se na fonte de distorções potencialmente muito sérias (p. 369). É esta a razão, conclui, de o capitalismo ser periodicamente assaltado por orgias especulativas que 
o colocam num pântano de destruição. Se ele está certo, é fácil concluir que esse processo é evidentemente potenciado, num contexto em que a financeirização dá o tom do processo de acumulação. A crise detonada pelo mercado imobiliário dos EUA em 2008 parece dar plena razão a essas suposições. Para o que nos interessa aqui, o importante a reter da argumentação de Harvey é a necessária assimilação do processo de acumulação a um movimento que é, em última instância, de rent seeking, questionando a ideia de que haveria uma incompatibilidade insolúvel entre acumulação de capital e rentismo.

Discutidas as versões contemporâneas da renda diferencial natural e produzida, é chegada a hora da discussão da renda absoluta. Como vimos, Marx vai criticar Ricardo por não ter contemplado sua possibilidade, já que, para ele, a existência desse tipo de renda é evidente e decorre do caráter monopólico da própria propriedade da terra. Considerando a questão da utilização da terra para fins de produção agrícola, Marx mostrou que a mera existência da propriedade ergue barreiras ao processo de equiparação na distribuição intersetorial da mais valia gerada pelo capital global, de modo que parte do valor excedente é subtraída ao processo de formação da taxa média de lucro. Contemporaneamente temos um tipo de renda absoluta que vem se tornando cada vez mais importante. Ele é, no entanto, estruturalmente diferente da renda absoluta a que Marx fez referência. Estamos falando da chamada "mercadoria conhecimento". Como há uma enorme literatura a esse respeito e uma profusão de hipóteses e considerações sobre o tema, cabe fazer algumas colocações iniciais para que fique claro de que forma entendemos a questão no presente trabalho.

Em primeiro lugar é preciso lembrar que o conhecimento enquanto tal nunca deixou de estar ligado aos processos produtivos. Foram os progressos no conhecimento, genericamente considerado, que criaram as condições para o surgimento da Revolução Industrial ao final do século XVIII e de todo o desenvolvimento posterior. Contudo, apesar de elemento indispensável, o conhecimento nunca foi variável a integrar o processo produtivo enquanto processo de produção de valor (e de valor excedente), pelo menos não diretamente. Do ponto de vista marxista, como se sabe, o processo de produção opera com dois tipos diferentes de capital, o capital variável, constituído pelas horas de trabalho compradas aos proprietários da força de trabalho, e o capital constante, constituído por todos os demais elementos desse processo (instalações, máquinas, insumos, matérias-primas etc.). O conhecimento está aí presente indiretamente, objetivado no capital constante, particularmente naquela parcela desse capital que toma a forma de capital fixo (ferramentas, equipamentos, máquinas etc.), além de estar presente também, sob a forma da habilidade dos trabalhadores, no capital variável. $\mathrm{O}$ valor relativo à produção do conhecimento enquanto tal não aparece em nenhum lugar, a não ser indiretamente no valor aumentado da mão de obra mais qualificada.

Mas o universo de consequências que a evolução do conhecimento tem sobre o processo material de produção não se resume a isso. E por que então esse elemento não aparece? A resposta, dada por Marx, é que o valor das mercadorias é determinado não pelo tempo de trabalho necessário à sua produção, mas pelo tempo de 
trabalho necessário à sua reprodução (1984/1895, p. 298). Assim, o valor de uma máquina não contém nenhum elemento relativo ao custo do saber que engendrou sua invenção, mas tão somente o custo das matérias-primas e outros insumos correntes, mão de obra e depreciação de capital fixo envolvido em sua fabricação, uma vez já inventada. De mais a mais, a crescente incorporação do conhecimento à produção ocorre sempre com vistas à obtenção de uma mais-valia extra (sobrelucro), o que passa pela redução do valor das mercadorias, de modo que seria uma contradição em termos se esse valor aparecesse diretamente.

Isso posto, qual é a novidade que o capitalismo contemporâneo traz? A novidade é a existência de mercadorias feitas só de conhecimento. O setor paradigmático desse tipo de mercadoria é o setor de informática. Cabe então perguntar: o que é um software, ou produtos correlatos a esse, que empresas como a Microsoft e a Google vendem aos milhares todos os dias? É algo que tem a forma mercadoria, pois tem um preço e o acesso a ela depende do pagamento desse preço, mas que não tem valor, pois o tempo de trabalho necessário à sua reprodução é zero. Qual é o fundamento desse preço então? Seu fundamento é uma renda do saber, uma renda absoluta, que, tal como a renda absoluta da terra que Marx diagnosticou, fundamenta-se pura e simplesmente na existência da propriedade. ${ }^{11}$

Marx disse sobre a propriedade fundiária que ela não produz em si mesma renda, mas que ela dá a seu detentor o poder de subtraí-la à produção agrícola até que o preço dos bens cuja produção ela possibilita sejam altos o suficiente para proporcionar-lhe uma renda, no caso, renda absoluta. Pois podemos dizer o mesmo da propriedade de um bem intangível como o software, mas que, ao contrário da terra, não se caracteriza pela escassez e sim pela abundância. O software, justamente pela sua natureza de bem sem valor (não é preciso trabalho para reproduzi-lo), tem o caráter de um bem livre, ou seja, abundante, e por isso não deveria ter preço. Mas quem detém a propriedade intelectual do software tem o poder de subtraí-lo à produção de outros bens (ou à sua utilização como bem final) se uma renda não lhe for paga. É essa propriedade juridicamente garantida que ergue barreiras à utilização do conhecimento objetivado no software, a menos que uma renda apareça para seu proprietário. ${ }^{12}$ Como não há aqui, como há no caso da propriedade agrícola, uma produção de valor acima do que é necessário para realizar os preços

\footnotetext{
${ }^{11}$ Esta interpretação sobre a natureza do valor monetário que é pago à propriedade intelectual está em linha com a de Haddad (2004) e Teixeira e Rotta (2012). Na medida em que equipara a renda do saber à renda da terra, a interpretação difere da de Prado (2005), que a aproxima do juro. Vale registrar, porém, que também o autor concorda com o caráter fortemente rent seeking desse tipo de empreendimento ( $\mathrm{pp}$. 109-110).

${ }^{12} \mathrm{Na}$ ciência econômica convencional, esses bens são chamados de toll goods (bens pedagiados). Eles se caracterizam por ser não rivais - o consumo do bem por um agente não impede seu consumo por outros - e excluíveis - apesar da não rivalidade que os caracteriza, agentes podem ser excluídos de seu consumo, por meio da imposição de um preço (pedágio). No caso da mercadoria conhecimento, porém, o que interessa do ponto de vista da economia política é o fato de que ela é uma mercadoria especial, diferenciada, por não levar trabalho em sua reprodução.
} 
de produção, não está no setor em si a renda a ser apropriada. A propriedade intelectual, ao tornar o conhecimento uma mercadoria e ao torná-lo um insumo praticamente indispensável à produção de todas as outras, obriga a transformação de parte do valor produzido nos demais setores em renda do saber, subtraindo, portanto, essa parcela de valor do processo de formação da taxa geral de lucro que engloba todos os demais setores. Assim, apesar de aparecer formalmente como lucro, o ganho das empresas que produzem esse tipo de bem é de fato constituído por renda, uma renda do saber, que se estabelece simplesmente porque alguém se apresenta como dono do conhecimento e, enquanto tal, exige uma renda para "liberá-lo" para os demais. Trata-se, portanto, de uma forma moderna de renda absoluta. Consideremos agora a forma moderna da renda de monopólio.

Quando apresentamos, na primeira seção, o Caso 6 - renda de monopólio utilizamos como exemplo a situação de uma terra que produz uma uva de excepcional qualidade e, por tabela, um vinho de excepcional qualidade. Se o caso em tela se resumisse a exemplos desse tipo, não teria a menor importância sistêmica, visto que, para sua ocorrência, seria necessária a conjunção de uma série de fatores excepcionais. Ele poderia ser, portanto, assimilado aos casos, referidos por Ricardo, e também por Marx, em que o valor (preço) das mercadorias não é regulado pelo tempo de trabalho necessário à sua produção, mas por sua escassez e pela disposição de pagar daqueles que desejam esses bens.

Não é essa, no entanto, a situação no capitalismo de hoje. Bem ao contrário, as propriedades mágicas que só seriam, em princípio, resultado da conjugação de circunstâncias excepcionais, são agora correntemente produzidas. A relação da mercadoria com sua marca é antiga, mas é nas últimas décadas que a marca ganha definitivamente lugar central na produção capitalista: "Até o início dos anos 1970, os logotipos em roupas geralmente ficavam escondidos, discretamente colocados na face interna dos colarinhos". No final dos anos 1970, eles estavam sendo "arrastados para o lado de fora das camisetas". No início dos anos 1980, já eram um "acessório de moda", que aos poucos foi engolindo as próprias roupas (Klein, 2008, p. 52). Considerando uma definição que aparece em quase todos os livros-texto de marketing, "marca é a união de atributos tangíveis e intangíveis, simbolizados em um logotipo, cujo fim é criar influência e gerar valor".

O objetivo maior da marca, portanto, não é simplesmente ajudar a vender a mercadoria, mas "gerar valor", produzir um price premium, ou, em nossos termos aqui, garantir uma renda de monopólio. Daí por que a marca ter se convertido num ativo, um patrimônio intangível, que faz parte dos ativos não circulantes da empresa, tanto quanto o imobilizado e os investimentos financeiros. ${ }^{13}$ Mas o fundamental não é que a marca tenha se transformado oficialmente num ativo. $\mathrm{O}$ fundamental é que esse ativo faça parte do grupo dos mais importantes, em detrimento do imobilizado, atrelado à produção enquanto tal (máquinas, equipa-

\footnotetext{
${ }^{13} \mathrm{O}$ valor da marca, tal como no caso da terra e das ações, é resultante da capitalização à taxa de juros vigente dos rendimentos futuros esperados por seu detentor, ou seja, trata-se de capital fictício.
} 
mentos e instalações físicas). É revelador o seguinte trecho de um celebrado manual de managering a respeito da forma de se organizar a contabilidade capitalista: "A capacidade de mobilização e exploração dos ativos intangíveis ou invisíveis tornou-se muito mais decisiva do que investir e gerenciar ativos físicos tangíveis" (Kaplan e Norton, apud Prado, 2005, p. 95).

Os ativos tangíveis são peças fundamentais para a apropriação do lucro normal, ou seja, para a realização do valor da mercadoria de modo a se obter por ela ao menos o preço de produção. Esses mesmos ativos, ao lado de outros intangíveis como tecnologia, são também as peças-chave da apropriação do sobrelucro, aquele valor excedente adicional que as empresas mais produtivas têm à sua disposição. Mas renda, renda de monopólio, só a marca é capaz de produzir. E ter sucesso no branding é muito mais interessante do que ser bem-sucedido numa inovação produtiva, porque libera o valor da mercadoria da camisa de força do tempo de trabalho socialmente necessário. Uma vez estabelecida, a marca não só singulariza a mercadoria, mas a torna independente, permite que ela domine o cliente, que deixa o preço de lado e paga o que for necessário. ${ }^{14}$ Atinge-se o ponto ideal do ponto de vista da valorização: o consumidor consome antes a marca do que o produto.

Para tratar das duas últimas categorias de rendimento pertencentes ao grupo das rendas (juros e dividendos), consideremos por fim as chamadas teses da financeirização. Chesnais (2005) foi dos primeiros autores marxistas a chamar a atenção para o ponto que realmente deve ser destacado: o caráter externo ao processo de produção enquanto tal que tem o capital portador de juros, uma vez que é vinculado à mera propriedade. A tese mais importante que deve ser mostrada, portanto, é que a lógica financeira, externa e estranha às necessidades da produção, foi internalizada no próprio espaço produtivo. Não se trata, portanto, de asseverar que a valorização financeira tornou-se mais importante do que a valorização produtiva (o que pode ou não ser verdade a depender de cada negócio e de cada momento específico da conjuntura). Não se trata também simplesmente de afirmar que, nas três últimas décadas, o crescimento da riqueza financeira se deu a um ritmo muito mais elevado que o crescimento da riqueza real (o que é verdadeiro, de qualquer forma, a julgar pelos dados). ${ }^{15}$ Não se trata tampouco de advogar que a valorização financeira tem se autonomizado em relação à valorização produtiva (ainda que, do ponto de vista categorial, exista, a meu ver, um processo de autonomização das formas sociais mais abstratas que está ontologicamente determinando a proemi-

\footnotetext{
${ }^{14}$ A semelhança com o conceito de capital simbólico desenvolvido por Bordieu (1992) é evidente: uma marca consolidada permite que uma determinada mercadoria coloque-se em posição de proeminência diante de suas concorrentes, o que fortalece seu poder de imposição. Traduzindo em termos marxistas, diríamos que, quando a marca ganha a centralidade do processo, superpõem-se duas camadas de fetiche: a originária da forma mercadoria e a adicional produzida pela marca. Fontenelle (2002) faz uma boa discussão em torno do fetiche redobrado criado pelo domínio e autonomização da marca utilizando como ilustração o caso do McDonald's. Ver a respeito também Arantes (2004).
}

${ }^{15}$ Conforme Paulani (2010). 
nência que vem assumindo o capital fictício). ${ }^{16}$ Trata-se de insistir que, para além da parcela do lucro que sempre assumiu a forma de renda pois, enquanto juro, é encarado inclusive como custo do capital, atualmente, pelo menos no que concerne aos capitais mais ou menos estabelecidos, é a posição externa do detentor de ações que acaba por comandar as decisões atinentes à produção. Hoje, além da pugna distributiva básica em torno do valor produzido, que coloca salários de um lado e lucros de outro, além de uma segunda "disputa" que coloca juro de um lado e lucro líquido de outro, há agora, de modo cada vez mais incisivo, uma terceira disputa, que coloca, de um lado, os lucros retidos (a serem reinvestidos) e, de outro, os lucros distribuídos aos detentores de ações (dividendos).

A profusão de títulos sobre governança corporativa que vêm sendo editados nos últimos anos parece indicar que essa percepção está correta. A tal governança, por sinal, não é nada mais do que a arte de tornar "parceiros" dos rentistas os gerentes dos processos produtivos. Se, no período dos anos dourados do capitalismo, esses administradores eram todo-poderosos para contrapor aos interesses dos acionistas os imperativos e necessidades da empresa enquanto tal, hoje, por meio de astutos expedientes como as stock options,${ }^{17}$ eles foram conquistados de vez pela finança. Finalmente, não custa lembrar que o caráter externo que a mera propriedade do capital, objetivada nas ações e títulos de dívida, assume perante o movimento real da produção transforma-a em força impessoal e por isso muito mais efetiva para impor exigências exorbitantes de rentabilidade (como os misteriosos $15 \%$, que se tornaram norma no mercado).

Resumindo, se quiséssemos definir de modo sumário o regime de acumulação contemporâneo, que arrasta consigo seu modo específico de regulação, talvez pudéssemos dizer que se trata de um capitalismo dominado pela finança, ${ }^{18}$ onde a acumulação se dá sob os imperativos da propriedade mais do que da produção e propriedade que é cada vez mais de capital fictício do que de meios de produção, um capitalismo, portanto, essencialmente rentista, onde o capital cada vez mais tem por argumento nomes, ao invés de terrenos e aparatos produtivos, enquanto os meios de produção revelam a importância cada vez maior dos ativos intangíveis, ao invés do trabalho vivo e do trabalho morto. Já que a mão de obra e as máquinas parecem estar sendo cada vez mais deslocadas pelo conhecimento e pela informação, já que os capitais associam-se em holdings cada vez mais afastadas do chão da produção, já que os capitalistas são cada vez mais difusos grupos de investidores associados em fundos, consórcios e private equitys, já que os principais ativos das empresas são imagens, marcas e patentes, parece que o capital terceirizou a explo-

\footnotetext{
${ }^{16}$ Ver a respeito Paulani (2014).

${ }^{17}$ Stock options são recompensas não monetárias oferecidas aos executivos da empresa, sob a forma de opções de compra de ações ordinárias da própria empresa a preços abaixo do mercado.

${ }^{18}$ Além da arguta observação referente à internalização no processo produtivo do caráter externo do capital portador de juros, Chesnais foi também dos primeiros marxistas a lançar e defender a tese de que o capitalismo atual é dominado pelas finanças.
} 
ração, delegou a outrem o trabalho de comandar a expropriação, deixou de lado o lucro e instalou-se confortavelmente nos espaços sociais que lhe garantem ganhos. Seus rendimentos agora não têm nada que ver com a atividade de explorar e ser explorado, eles são "direitos" que a propriedade lhe confere. ${ }^{19}$ Diante disso, não há espantar em que o fim do trabalho tenha sido decretado.

A importância de resgatar a teoria da renda de Marx está em mostrar que o fundamento de vários dos fenômenos que têm caracterizado a etapa atual do capitalismo está no mesmo lugar onde sempre esteve: o velho e conhecido trabalho não pago, por mais que o conhecimento de fato tenha crescido de importância no processo produtivo, por mais que as marcas e patentes venham pontificando ante os ativos convencionais, por mais que a finança pareça dispensar a produção efetiva. Ainda que seja impossível compreender a forma contemporânea de operar do capital, sem atentar para esses fenômenos é preciso observar que todos esses são traços distintivos desse modo de produção: é parte constitutiva de seu funcionamento o aprimoramento do conhecimento, da técnica e da ciência, empurrados que são pelas exigências da concorrência; é sua tendência imanente a fuga das normas de regulação socialmente postas, a libertação dos torniquetes impostos pela concorrência, que as prerrogativas monopólicas propiciam; finalmente, é tendência natural do sistema, em condições normais, que a finança vá assumindo o controle, mais liberta que é perante a acumulação produtiva, dos entraves e estorvos representados pela necessidade de fixar o capital material e de extrair valor excedente de uma força que é viva, quer autonomia, tem direitos e se rebela. Se agora há uma diferença é de grau mais do que de substância, ou, em outras palavras, trata-se de uma situação que o funcionamento normal do capitalismo produziria de qualquer jeito. A transferência cada vez mais acentuada da produção para a propriedade enquanto base de justificação da remuneração do capital é apenas a forma mais adequada, do ponto de vista da configuração dos rendimentos, de dar conta desta etapa avançada do capitalismo.

\section{REFERÊNCIAS BIBLIOGRÁFICAS}

Arantes, Paulo E. (2004). “Beijando a cruz”. In Arantes, Paulo E. Zero a Esquerda. São Paulo: Conrad. Bercovici, Gilberto (2011) Direito Econômico do Petróleo e dos Recursos Naturais. São Paulo: Quartier Latin.

Bordieu, Pierre (1992) O Capital Simbólico. Rio de Janeiro: Bertrand Brasil.

Bresser-Pereira, L.C. (2008) “The Dutch disease and its neutralization: A Ricardian approach”. Revista de Economia Política, volume 28 (1): 47-71.

Chesnais, François (2010) “A proeminência da finança no seio do capital em geral, o capital fictício e o

\footnotetext{
${ }^{19}$ Numa chave um tanto distinta, Zizek (2012) esboça argumento semelhante ao afirmar que atualmente a extração de valor excedente não deriva principalmente da exploração da força de trabalho, mas está associada a rendas econômicas de bens públicos privatizados, com destaque para os recursos naturais e o "general intellect" a que se referiu Marx.
} 
movimento contemporâneo de mundialização do capital”. In Chesnais, François et alii. A Finança Capitalista. São Paulo: Alameda: pp.95-182.

Duménil, Gerard e Dominique Lévy (2010) “A finança capitalista: Relações de produção e relações de classe”. In Chesnais, François et alii. A Finança Capitalista. São Paulo: Alameda: 183-246.

Fix, Mariana de A. B. (2011) Financeirização e Transformações Recentes no Circuito Imobiliário no Brasil - Tese de Doutoramento, IE Unicamp.

Fontenelle, Isleide (2002) O Nome da Marca. São Paulo: Boitempo.

Haddad, F. (2004) Trabalho e Linguagem: para a Renovação do Socialismo. São Paulo: Azougue.

Harvey, David (2006/1982). Limits to Capital. London: Verso Books.

Husson, Michel (2010) "Finança, hiperconcorrência e reprodução do capital”. In Chesnais, François et alii. A Finança Capitalista. São Paulo: Alameda.

Klein, Naomi (2008) Sem Logo. Rio de Janeiro: Record

MARX, Karl (1984/1895) O Capital. Volume III, Tomo I. In: Marx, Coleção “Os Economistas”. São Paulo: Abril Cultural.

MARX, Karl (1985/1895). O Capital. Volume III, Tomo II. In: Marx, Coleção “Os Economistas”. São Paulo: Abril Cultural.

MARX, Karl (1983). “O rendimento e suas fontes (Teorias da mais valia). In: Marx, coleção "Os Pensadores”. São Paulo: Abril Cultural.

Paulani Leda M. (2010) "Brazil in the crisis of finance-led regime of accumulation. Review of Radical Political Economics, volume 42 (3), pp. 363-372.

Paulani Leda M. (2014). "Money in contemporary capitalism and the autonomization of capitalist forms in Marx's theory”. Cambridge Journal of Economics, volume 38, n4, pp.779-798

Prado, Eleutério F. S. (2005). A Desmedida do Valor. São Paulo: Xamã.

Teixeira, Rodrigo A. e Rotta, T. N. (2012) "Valueless knowledge-commodities and financialization: productive and financial dimensions of capital autonomization”. Review of Radical Political Economics, volume 44, (1), pp. 448-467.

Zizek, S. (2012) "The revolt of salaried bourgeoisie". , 34(2): 9-10. 